\title{
Correction to: Performance Evaluation and Social Optimization of an Energy-Saving Virtual Machine Allocation Scheme within a Cloud Environment
}

\author{
Xiushuang Wang ${ }^{1}$. Jing Zhu ${ }^{1}$. Shunfu $\operatorname{Jin}^{1}$ (D) Wuyi Yue ${ }^{2}$. \\ Yutaka Takahashi ${ }^{3}$
}

() Operations Research Society of China, Periodicals Agency of Shanghai University, Science Press, and Springer-Verlag GmbH Germany, part of Springer Nature 2020, corrected publication 2020

\section{Correction to: Journal of the Operations Research Society of China https://doi.org/10.1007/s40305-019-00272-x}

The authors would like to correct the style of their names in the original publication. The correct style of author names is provided in this correction.

Xiushuang Wang, Jing Zhu, Shunfu Jin, Wuyi Yue, Yutaka Takahashi.

The original article has been corrected.

The original article can be found online at https://doi.org/10.1007/s40305-019-00272-x.

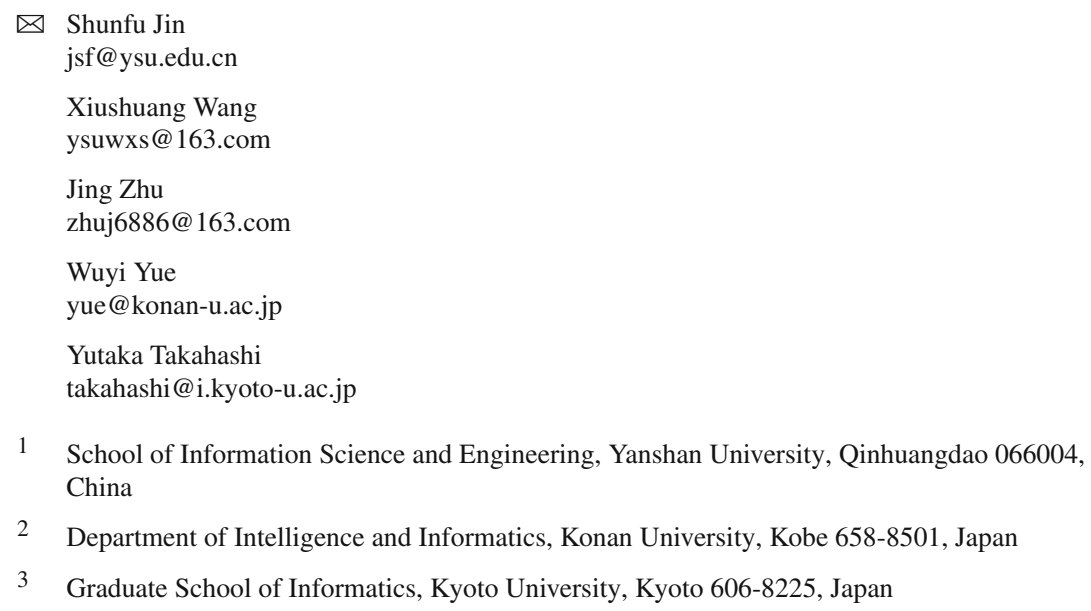

